\title{
Optimizing in-hospital triage for large vessel occlusion using a novel clinical scale $\left(\mathrm{GAI}_{2} \mathrm{AA}\right)$
}

Tsuyoshi Ohta, MD, PhD, Ichiro Nakahara, MD, PhD, Shoji Matsumoto, MD, PhD, Daisuke Kondo, MD, Sadayoshi Watanabe, MD, Kenji Okada, MD, Maki Fukuda, MD, Noritaka Masahira, MD, PhD, Takaya Tsuno, MD, PhD, Toshiki Matsuoka, MD, Mitsuhiro Takemura, MD, Hitoshi Fukuda, MD, PhD, Naoki Fukui, MD, and Tetsuya Ueba, MD, PhD

Neurology ${ }^{\circledR}$ 2019;93:e1997-e2006. doi:10.1212/WNL.0000000000008550

\section{Abstract}

\section{Objective}

To identify a proximal anterior circulation occlusion for effectively administering immediate mechanical thrombectomy by developing a novel, simple diagnostic scale to predict the occlusion, to compare its validity with available scales, and to assess its utility.

\section{Methods}

To develop a novel clinical scale, we retrospectively analyzed a cohort of 429 patients with acute ischemic stroke from a single center. The novel scale $\mathrm{GAI}_{2} \mathrm{AA}$ was applied to a prospective cohort of 259 patients from 3 stroke centers for external validation. The utility of the scale as an in-hospital triage was compared for the temporal factors of 158 patients with the occlusion.

\section{Results}

In a scale-developmental phase, those with a proximal anterior circulation occlusion had significantly more frequent signs of hemispheric symptoms, including gaze palsy, aphasia, inattention, arm paresis, and atrial fibrillation. The $\mathrm{GAI}_{2} \mathrm{AA}$ scale was developed using consolidated hemispheric symptoms and was scored as follows: score $=2$, arm paresis score $=1$, and atrial fibrillation score $=1$. A cutoff value $\geq 3$ was optimal for the correlation between sensitivity $(88 \%)$ and specificity $(81 \%)$, with a C statistic of 0.90 (95\% confidence interval 0.87-0.93). External validation indicated that discrimination was significantly better than or not different from that of available complex scales. Door-to-puncture time was significantly reduced (91 $[82-111]$ vs $52[32-75]$ minutes, $p<0.001)$.

\author{
Correspondence \\ Dr. Ohta \\ tsuyoshi@ya2.so-net.ne.jp
}

\section{RELATED ARTICLE}

\section{Editorial}

Predicting large vessel occlusion with a clinical scale: Building a better mousetrap

Page 951

\section{Conclusion}

The GAI $_{2} \mathrm{AA}$ scale showed high sensitivity and specificity when an optimal cutoff score was used and was useful as an in-hospital triage tool. 


\section{Glossary}

DAWN = DWI or CTP Assessment With Clinical Mismatch in the Triage of Wake-Up and Late Presenting Strokes Undergoing Neurointervention With Trevo; DEFUSE 3 = Endovascular Therapy Following Imaging Evaluation for Ischemic Stroke; GAI = gaze palsy, aphasia, or inattention; ICA = internal carotid artery; MRA = magnetic resonance angiography; NIHSS = NIH Stroke Scale; OR = odds ratio; PASS = Prehospital Acute Stroke Severity; ROC = receiver operating characteristic; 3I-SS = 3Item Stroke Scale.

Stroke is associated with 43.7 million (3.2\%) annual disabilityadjusted life-years worldwide. ${ }^{1}$ Mechanical thrombectomy, particularly initiated within 6 hours from the onset of symptoms, is recommended for patients with ischemic stroke due to a proximal anterior circulation occlusion. ${ }^{2-7}$ Rapid recognition of the occlusion is essential for earlier initiation of mechanical thrombectomy. ${ }^{8,9}$

Several clinical scales are available to predict occlusions. ${ }^{10-12}$ However, selection according to these scales may miss a candidate or include the majority of patients. ${ }^{13}$ The role of these scales as an adequate patient triage to preclude the use of intracranial arterial imaging has been unclear. ${ }^{9,13}$

We aimed to develop a novel, simple diagnostic scale, called $\mathrm{GAI}_{2} \mathrm{AA}$, to externally validate its generalizability for predicting a proximal anterior circulation occlusion, to compare its validity with the available scales, and to assess the reduction of door-to-puncture time using the scale for an in-hospital triage.

\section{Methods}

\section{Study purpose, design, and eligibility criteria}

This prediction model study, conducted in accordance with the guidelines of the Transparent Reporting of a Multivariable Prediction Model for Individual Prognosis or Diagnosis, ${ }^{14}$ included 3 phases. The first was a scale-developmental phase, a retrospective nonblinded cohort study, that retrospectively analyzed patients' clinical variables and established a novel diagnostic scale. The second phase, a prospective external validation cohort study, analyzed a new dataset to assess the generalizability of the novel scale and to compare its predictive performance with the available scales. The third phase, a retrospective cohort study, compared the temporal factors associated with mechanical thrombectomy before and after the introduction of the scale.

Acute ischemic stroke was defined as a focal or global neurologic deficit with symptoms thought to be of vascular origin but without evidence of intracranial hemorrhage. ${ }^{15}$ We included only patients with acute ischemic stroke who arrived within 4.5 hours from the onset of symptoms because good reperfusion should be achieved as early as possible without detailed clinical/perfusion imaging mismatch if treatment can be initiated within 6 hours of symptom onset. ${ }^{7}$ Patients were administered IV alteplase before vascular imaging if deemed appropriate by the attending physician. Patients with suspected TIA with no symptoms during the assessment in the emergency room were excluded from the analysis. ${ }^{15}$

\section{Imaging protocols and definition of a proximal anterior circulation occlusion}

We used noncontrast CT, MRI, or both to diagnose ischemic stroke. Patients diagnosed with ischemic stroke were sequentially evaluated for an occlusion with magnetic resonance angiography (MRA), CT angiography, or cerebral angiography within 6 hours from onset. CT angiograms were acquired with a 64- or 320-slice multidetector-row CT scanner. Timeof-flight MRA data of the intracranial arteries were acquired with $1.5 \mathrm{~T}$ or $3 \mathrm{~T}$ magnetic resonance scanners.

Proximal anterior circulation occlusion was defined as unilateral acute complete symptomatic occlusion of the intracranial internal carotid artery (ICA) and M1 and proximal M2 segments of the middle cerebral artery. Occlusions of other cerebral vessels such as the anterior cerebral or basilar artery were excluded.

Vascular risk factors and neurologic evaluation The vascular risk factors of hypertension, hypercholesterolemia, diabetes mellitus, and atrial fibrillation (AF) were diagnosed on admission according to self-reported history or the standard definitions of blood pressure $>160 / 90 \mathrm{~mm} \mathrm{Hg}$, low-density lipoprotein cholesterol $>4.1 \mathrm{mmol} / \mathrm{L}$, National Glycohemoglobin Standardization Program standards for glycated hemoglobin $>6.5 \%$, and ECG findings. ${ }^{16-19}$ The presence of AF included a history of paroxysmal and persistent $\mathrm{AF}$ and newly diagnosed AF detected on the ECG acquired in the ambulance. Alcohol consumers were defined as those consuming an average of $>7$ standard drinks weekly. ${ }^{20}$ Patients with a history of smoking within 5 years of admission were classified as smokers. ${ }^{21}$

The medical records were retrospectively reviewed for the presence of each subitem of the NIH Stroke Scale (NIHSS). The exact NIHSS was scored on admission by a stroke-trained hospital physician.

\section{Strategies for the development of a novel scale to predict the occlusion}

To calculate a valid sample size, we assumed that the frequency of a large artery occlusion as the cause of acute ischemic stroke was $28 \%$ to $46 \%,{ }^{22,23}$ requiring a sample size with a $95 \%$ confidence interval of $10 \%$ (range $310-382){ }^{24}$ 
The retrospective cohort included patients treated from September 2012 to February 2017 from a single center in Kochi, Japan.

We designed a simple scoring system. Grading of severity or a complex flowchart was not applied. To determine an appropriate scale, patients' baseline characteristics, including neurologic findings, were compared between patients with and those without an occlusion. We analyzed the clinical variables to identify those that predicted the occlusion. Univariate analyses were initially used to select variables with the highest discriminatory value in our retrospective cohort of patients with acute ischemic stroke. Multivariable logistic regression analysis was performed a priori on the basis of clinical relevance for differences associated with a value of $p<0.20$ on univariate analysis. ${ }^{25}$ Predictive models were created to select significant variables on the guiding principle of parsimony. Coefficients derived from the multivariable logistic regression analysis were used to weigh the significance of each factor.

The optimal threshold of the novel scale to discriminate the occlusion was determined from receiver operating characteristic (ROC) curve analysis, i.e., values nearest the upper-left corner of the curve. The significance of the threshold was evaluated for the ability to discriminate between the severity of neurologic deficits on the basis of NIHSS values of $<6$ or $\geq 6$. $^{5}$

\section{Prospective external validation}

We conducted a prospective external validation study using a new cohort of patients to show its generalizability. ${ }^{14} \mathrm{We}$ intended to include a minimum of 100 events as suggested for externally validating a prognostic model. ${ }^{26}$ Thus, we included 250 patients representing $\approx 40 \%$ of the population with an occlusion according to a previous survey at each center. We conducted a 12-month study of the patients from the stroke centers in Kochi, Aichi, and Fukuoka, Japan, based on the results of statistical analyses. Thus, from March 2017 to February 2018, patients with acute ischemic stroke who were admitted within 4.5 hours from the onset of symptoms were assigned $\mathrm{GAI}_{2} \mathrm{AA}$ scale scores by a stroke-trained hospital physician on arrival before vascular imaging and were diagnosed to detect the occlusion. If the presence of $\mathrm{AF}$ was unclear, it was not scored.

The accuracy and reliability of prediction with the $\mathrm{GAI}_{2} \mathrm{AA}$ scale were compared with simple clinical scales, including the Prehospital Acute Stroke Severity (PASS) scale, ${ }^{10}$ the Cincinnati Prehospital Stroke Severity Scale, ${ }^{12}$ the 3-Item Stroke Scale (3I-SS), ${ }^{27}$ the Field Assessment Stroke Triage for Emergency Destination, ${ }^{11}$ and the Rapid Arterial Occlusion Evaluation Scale. ${ }^{28}$ The Ambulance Clinical Triage For Acute Stroke Treatment and Los Angeles Motor Scale were not compared because they included various conditions administered by paramedics in the field, which could not be retrieved from our collected data. ${ }^{29,30}$ The accuracy of the predictions was evaluated for the sensitivity and specificity of each optimal cutoff value. The $\mathrm{C}$ statistic was used to assess discrimination. The optimal cutoff points of the scores were defined according to published data. ${ }^{10-12,27,28}$

\section{Comparison of the temporal factors associated with mechanical thrombectomy before and after the introduction of the $\mathrm{GAl}_{2} \mathrm{AA}$ scale}

The temporal factors were compared for patients with occlusion who were treated endovascularly $\leq 6$ hours at a single center in Kochi, Japan. From January 2015 to February 2017, MRA was usually used to identify the occlusion subsequent to head CT. After the introduction of the $\mathrm{GAI}_{2} \mathrm{AA}$ scale, from March 2017 to January 2019, the patients with a score $\geq 3$ on arrival were considered candidates for direct transfer to an angiographic suite. The patients were scored with this scale by a stroke-trained hospital physician largely depending on the information provided by the emergency department staff. The exact score of the $\mathrm{GAI}_{2} \mathrm{AA}$ scale was decided by the physician owing to the trial design, which adopted a stroke-trained physician as the sole scorer and designated the decision regarding the use of the angiographic suite to the physician/ neurointerventionalist, thereby ensuring consistency throughout the trial duration. If deemed appropriate by the stroke-trained physician/neurointerventionalist after discussions pertaining to the detailed information obtained from family members or relatives, the rationality of the relationship between the paralyzed side and the hemispheric symptoms, the high NIHSS score, or the hyperdense cerebral artery signs in head CT images, patients with a score $\geq 3$ on arrival were directly transferred to the angiographic suite subsequent to head CT. Patients with a score of 0,1 , or 2 were treated similarly as previously reported. Good reperfusion, door-topuncture time, and door-to-recanalization time were defined on the basis of the previous reports. ${ }^{2,31}$

\section{Data collection and ethics}

Data were anonymously analyzed. Missing data were reviewed and added from a second review of medical records. The requirement for a signed informed consent was waived because the guidelines of the institutional ethics review board of each stroke center that approved this study stated that the waiver presented no more than minimal risk of harm to participants and involved no procedures requiring written consent (approvals KHSC161063, KMH17111503, and HM17-394).

\section{Statistical analysis}

Dichotomous categorical data such as sex, vascular risk factors, and prehospital functional independence were analyzed with the Fisher exact test. The Mann-Whitney $U$ test was used to analyze ordinal or nonparametric, continuous data such as the NIHSS score, age, onset-to-admission time, and glucose level. Values for noncategorical data are presented as the median and the $25 \%$ to $75 \%$ interquartile range. Explanatory variables for multivariable logistic regression models were limited to $\approx 10 \%$ of patients in the less frequent category. ${ }^{32}$ The logistic regression equation included the significant variables and their coefficients. The outcome variable was 
expressed as the logit, a natural log (base $e$ ) of the odds ratio (OR). ORs and their 95\% confidence intervals were calculated for significantly associated variables.

The statistical significance of the discriminative difference between the scales was tested with the DeLong test for 2 correlated ROC curves. ${ }^{33}$ The calibration of he model was assessed for goodness of fit by plotting the estimated probability of each score on the $\mathrm{x}$-axis against the observed probability along the $y$-axis compared with the diagonal line, representing perfect calibration. The threshold for statistical significance was $p<0.05$. All statistical analyses were performed with EZR version 1.27.23 (Saitama Medical Center, Jichi Medical University, Saitama, Japan). ${ }^{34}$

\section{Data availability}

Anonymized data will be shared by request from any qualified investigator.

\section{Results}

\section{Development of the novel $\mathrm{GAI}_{2} \mathrm{AA}$ scale predicting occlusion}

Figure 1 shows the flow diagram of this retrospective cohort.

\section{Comparison of patient baseline characteristics and neurologic deficits between patients with and without occlusions}

Table 1 shows comparisons of the baseline characteristics of patients with and without occlusions. Univariate analyses revealed that patients with an occlusion were significantly older and had a higher NIHSS score, higher body mass index,

Figure 1 Flow diagram of the retrospective cohort

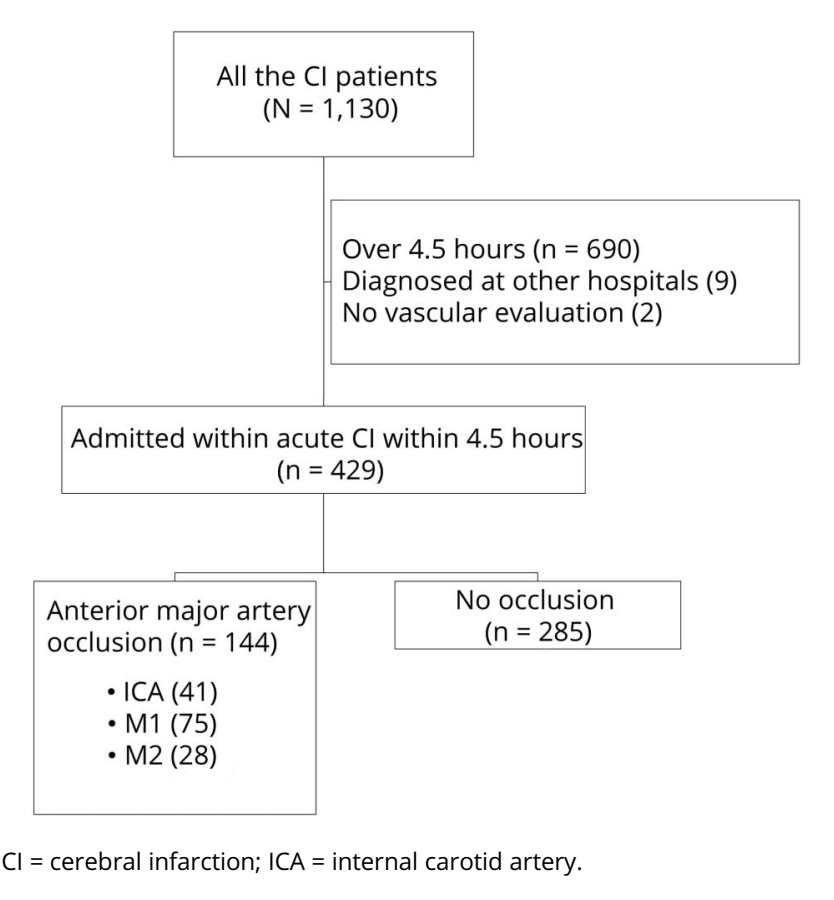

and higher prevalence of AF and lower prevalence of hyperlipidemia. Multivariable logistic regression analysis revealed that a higher NIHSS score on admission and presence of AF differed significantly between patients with or without an occlusion (table 1).

To identify crucial subitems of the NIHSS, neurologic deficits were compared between patients with and those without occlusions. Univariate analysis revealed a significant difference for each factor $(p<0.001)$. Multivariable analysis revealed that gaze palsy, facial palsy, arm paresis, aphasia, and inattention were significant independent predictors of occlusions (table 2).

\section{Multivariable logistic regression analysis of the associations of patients' characteristics and neurologic deficits}

We refined the variables to develop a simple scale. Gaze palsy, aphasia, and inattention are hemispheric and complement each other; these symptoms suggest the presence of hemispheric dysfunction. The coexistence of these symptoms does not increase the probability of an occlusion. These symptoms were consolidated and called GAI, indicating the presence of any of the following: gaze palsy, aphasia, or inattention. The factor arm paresis, not facial palsy, was selected because of its associated higher OR in the multivariable analysis of neurologic deficits (OR 2.9 for arm paresis, OR 2.1 for facial palsy) (table 3).

Multivariable logistic regression analysis revealed that a proximal anterior circulation occlusion was associated with the independent factors GAI, arm paresis, and AF, which was calculated as follows: logit (probability of the occlusion) $=3.3$ $(\mathrm{GAI})+1.5$ (arm paresis $)+1.3(\mathrm{AF})-4.4+e$. The points of the estimated vs observed values of the occlusion were close to the diagonal line, which indicated the excellent estimate of the model of outcome (figure 2A).

\section{Evaluation of the $\mathrm{GAI}_{2} \mathrm{AA}$ scale for predicting occlusions}

The $\mathrm{GAI}_{2} \mathrm{AA}$ scale was created from the data presented above. This scale estimates the risk of a proximal anterior circulation occlusion in patients with acute ischemic stroke on hospital arrival. This scheme assigns 2 points if GAI is present and 1 point each for arm paresis and AF. If we considered the interactions between factors, the point would be different between AF and arm paresis. However, we gave priority to simplicity and applied 1 point to each factor.

Scores of the $\mathrm{GAI}_{2} \mathrm{AA}$ scale $=2$ (if any of GAI is present $)+1$ (arm paresis) $+1(\mathrm{AF})$.

\section{Predictive value and discrimination ability of the $\mathrm{GAl}_{2} \mathrm{AA}$ scale}

The $\mathrm{GAI}_{2} \mathrm{AA}$ scale score significantly correlated with an occlusion. Specifically, higher scores augmented the probability 
Table 1 Baseline characteristics and multivariable logistic regression analysis of included factors of the retrospective cohort

\begin{tabular}{|c|c|c|c|c|c|}
\hline Factor & Proximal anterior circulation occlusion $(n=144)$ & No occlusion $(n=285)$ & $p$ Value & $\begin{array}{l}\text { Odds } \\
\text { ratio }\end{array}$ & $95 \% \mathrm{Cl}$ \\
\hline Age, y & $81(73-87)$ & $77(69-85)$ & 0.007 & 0.99 & $0.97-1.02$ \\
\hline Male, $\mathbf{n}(\%)$ & $72(50)$ & $156(55)$ & 0.36 & NA & NA \\
\hline Onset to vascular image, $\min$ & $144(112-196)$ & $141(102-201)$ & 0.82 & NA & NA \\
\hline BMI, $\mathrm{kg} / \mathrm{m}^{2}$ & $22.1(19.6-24.4)$ & $22.8(20.8-25.4)$ & 0.023 & 0.98 & $0.91-1.05$ \\
\hline BS, mmol/L & $6.8(6.0-7.9)$ & $6.7(5.8-8.1)$ & 0.65 & NA & NA \\
\hline NIHSS score on admission & $16(12-21)$ & $3(2-6)$ & $<0.001$ & 1.19 & $1.15-1.23$ \\
\hline$A F, n(\%)$ & $93(65)$ & $68(24)$ & $<0.001$ & 4.11 & $2.41-7.02$ \\
\hline Hypertension, n (\%) & $116(81)$ & $223(78)$ & 0.62 & NA & NA \\
\hline Hyperlipidemia, n (\%) & $38(26)$ & $107(38)$ & 0.023 & 0.70 & $0.39-1.24$ \\
\hline DM, n (\%) & $32(22)$ & $78(27)$ & 0.29 & NA & NA \\
\hline Previous ischemic stroke, n (\%) & $39(27)$ & $63(22)$ & 0.28 & NA & NA \\
\hline Alcohol, n (\%) & $49(34)$ & $114(40)$ & 0.25 & NA & NA \\
\hline Smoking, n (\%) & $52(36)$ & $121(42)$ & 0.21 & NA & NA \\
\hline IV alteplase, n (\%) & $99(69)$ & $168(59)$ & 0.058 & NA & NA \\
\hline Premorbid mRS score $\geq 2, n$ (\%) & $35(24)$ & $52(18)$ & 0.16 & NA & NA \\
\hline
\end{tabular}

Abbreviations: AF = atrial fibrillation; $\mathrm{BMI}=$ body mass index; $\mathrm{BS}=$ blood sugar; $\mathrm{Cl}$ = confidence interval; $\mathrm{DM}$ = diabetes mellitus; $\mathrm{mRS}$ = modified Rankin Scale; $\mathrm{NA}=$ not available; NIHSS = NIH Stroke Scale.

of the occlusion. Figure 2B shows the ROC curve analysis. The precise NIHSS scores on admission were significantly lower for patients with a $\mathrm{GAI}_{2} \mathrm{AA}$ scale score of 0,1 , or 2 compared with those with scores of 3 or 4 (3 [1-4] vs $16[13-21], p<0.001)$, indicating that $\mathrm{GAI}_{2} \mathrm{AA}$ scale scores reflected the severity of NIHSS scores on admission.

\section{Prospective external validation}

Patient characteristics and the $\mathrm{GAl}_{2} \mathrm{AA}$ scale scores of a prospective cohort

From March 2017 to February 2018, 1,515 patients with stroke with onset within 1 week were admitted to the 3 stroke centers, and 259 patients with ischemic stroke were admitted within 4.5 hours from onset, of whom 100 patients had a proximal anterior circulation occlusion (27 ICAs, $49 \mathrm{M} 1 \mathrm{~s}$, and $24 \mathrm{M} 2 \mathrm{~s}$ ). The $\mathrm{GAI}_{2} \mathrm{AA}$ scale significantly correlated with the occlusions. Figure 2C shows the ROC curve analysis of the prospective cohort. The precise NIHSS score on admission was significantly lower for patients with $\mathrm{GAI}_{2} \mathrm{AA}$ scale scores of 0,1 , or 2 vs 3 or $4(2[1-5]$ vs 15 [11-22], $p<0.001)$.

Accuracy and reliability of the $\mathrm{GAI}_{2} \mathrm{AA}$ scale compared with other scales

When applied to the retrospective and prospective cohorts, the ability of the $\mathrm{GAI}_{2} \mathrm{AA}$ to discriminate (C statistic) was significantly better than the PASS and 3I-SS and not significantly different from the others (table 4).

\section{Comparison of the temporal factors before and} after introduction of the scale

Of 158 patients with proximal anterior circulation occlusion, 115 were treated with mechanical thrombectomy from January 2015 to January 2019. Of 61 patients treated after the introduction of the $\mathrm{GAI}_{2} \mathrm{AA}$ scale as an in-hospital triage, $37(61 \%)$ were directly transferred to the angiographic suite and subsequently underwent mechanical thrombectomy. Among the 39 patients who were directly transferred to the angiographic suite, 2 did not show significant occlusion. One had mutism due to dementia, which could not be confirmed before the angiography. The other showed incomplete but significant recanalization probably due to IV alteplase infusion. Door-to-puncture time was significantly reduced $(91[82-111]$ vs $52[32-75]$ minutes, $p<0.001)$ (figure $3 \mathrm{~A}$ ).

The frequency of good reperfusion ( $89 \%$ vs $82 \%, p=0.43$ ) and groin puncture-to-recanalization time $(46[30-74]$ vs 39 [29-74] minutes, $p=0.64$ ) (figure 3B) were not significantly different between the 2 groups, resulting in a significant reduction of onset-to-recanalization time (241 [205-298] vs 200 [149-275] minutes, $p=0.0098$ ) (figure 3C). 
Table 2 Multivariable logistic regression analysis of neurologic findings of the retrospective cohort

\begin{tabular}{|c|c|c|c|c|}
\hline Factor, $\mathbf{n}(\%)$ & Proximal anterior circulation occlusion $(n=144)$ & No occlusion $(n=285)$ & Odds ratio & $95 \% \mathrm{Cl}$ \\
\hline LOC & $84(58)$ & $49(17)$ & 1.9 & $0.96-3.9$ \\
\hline LOC questions & $104(72)$ & $71(25)$ & 1.1 & $0.50-2.6$ \\
\hline LOC command & $75(52)$ & $31(11)$ & 0.77 & $0.31-1.9$ \\
\hline Best gaze & $107(74)$ & $35(12)$ & 4.4 & $2.1-9.0$ \\
\hline Visual fields & $41(28)$ & $26(9.1)$ & 1.2 & $0.55-2.6$ \\
\hline Facial palsy & $118(82)$ & $139(49)$ & 2.1 & $1.0-4.3$ \\
\hline Motor arm & $135(94)$ & $169(59)$ & 2.9 & $1.1-7.8$ \\
\hline Motor leg & $128(89)$ & $154(54)$ & 0.76 & $0.32-1.8$ \\
\hline Limb ataxia & $0(0)$ & $18(6.3)$ & $<0.001$ & 0-Infinity \\
\hline Sensory & $82(57)$ & $93(33)$ & 1.1 & $0.55-2.6$ \\
\hline Best language & $91(63)$ & $47(16)$ & 2.5 & $1.1-6.0$ \\
\hline Dysarthria & $119(83)$ & $185(65)$ & 0.73 & $0.34-1.6$ \\
\hline Extinction and inattention & $105(73)$ & $31(11)$ & 4.1 & $1.9-8.8$ \\
\hline
\end{tabular}

Abbreviations: $\mathrm{Cl}=$ confidence interval; $\mathrm{LOC}=$ level of consciousness.

\section{Discussion}

\section{Study implications}

The $\mathrm{GAI}_{2} \mathrm{AA}$ scale, comprising 3 factors, accurately predicts a proximal large anterior circulation occlusion with high sensitivity and specificity using an optimal cutoff value and is useful as an in-hospital triage tool.

\section{Simple clinical scales predicting large vessel occlusions}

Rapid identification of the occlusion may shorten the time to start mechanical thrombectomy. High NIHSS scores are used to predict occlusion. ${ }^{35}$ However, field assessment of the NIHSS is lengthy and therefore infrequently performed. ${ }^{9}$ Several simple scales were designed and validated for rapid identification. ${ }^{9,12,27,28,36-41}$

An ideal scale should have high sensitivity, good specificity, and apparent cutoff values acquired from a limited range of scores. Simple clinical scales combining NIHSS subitems provide a gross estimate of the presence or absence of an occlusion. ${ }^{9}$ However, clinically relevant thresholds of each scale are uncertain. For example, a scale with high specificity and low sensitivity such as the 3I-SS would miss a significant number of patients with occlusions. In contrast, a scale with low specificity such as PASS may include most patients. ${ }^{13}$ Thus, these scales are invalid without optimal cutoff values.

Clinical scales such as the Field Assessment Stroke Triage for Emergency Destination, Rapid Arterial Occlusion Evaluation scale, and 3I-SS use a complex staged scoring of certain symptoms and require special practice for accurate application; the available simple scales must not omit vessel imaging. ${ }^{9}$

\section{Superiority of the $\mathrm{GAI}_{2} \mathrm{AA}$ scale}

Our novel $\mathrm{GAI}_{2} \mathrm{AA}$ scale comprises hemispheric symptoms as a block, arm paresis, and the clinical risk factor $\mathrm{AF}$, with double weighting of the hemispheric symptoms, on the basis

Table 3 Multivariable logistic regression analysis depending on factors of the retrospective cohort

\begin{tabular}{lllll}
\hline & Coefficient & Standard error & Odds ratio & 95\% Cl \\
\hline Any of GAI & 3.3 & 0.36 & 26 & $13-52$ \\
\hline Arm paresis & 1.5 & 0.43 & 4.3 & $1.8-9.8$ \\
\hline AF & 1.3 & 0.29 & 3.5 & $2.0-6.3$ \\
\hline Intercept & -4.4 & 0.48 & 0.012 & $0.0048-0.031$
\end{tabular}

Abbreviations: $\mathrm{AF}=$ atrial fibrillation; $\mathrm{Cl}$ = confidence interval; $\mathrm{GAl}$ = gaze palsy, aphasia, or inattention . 

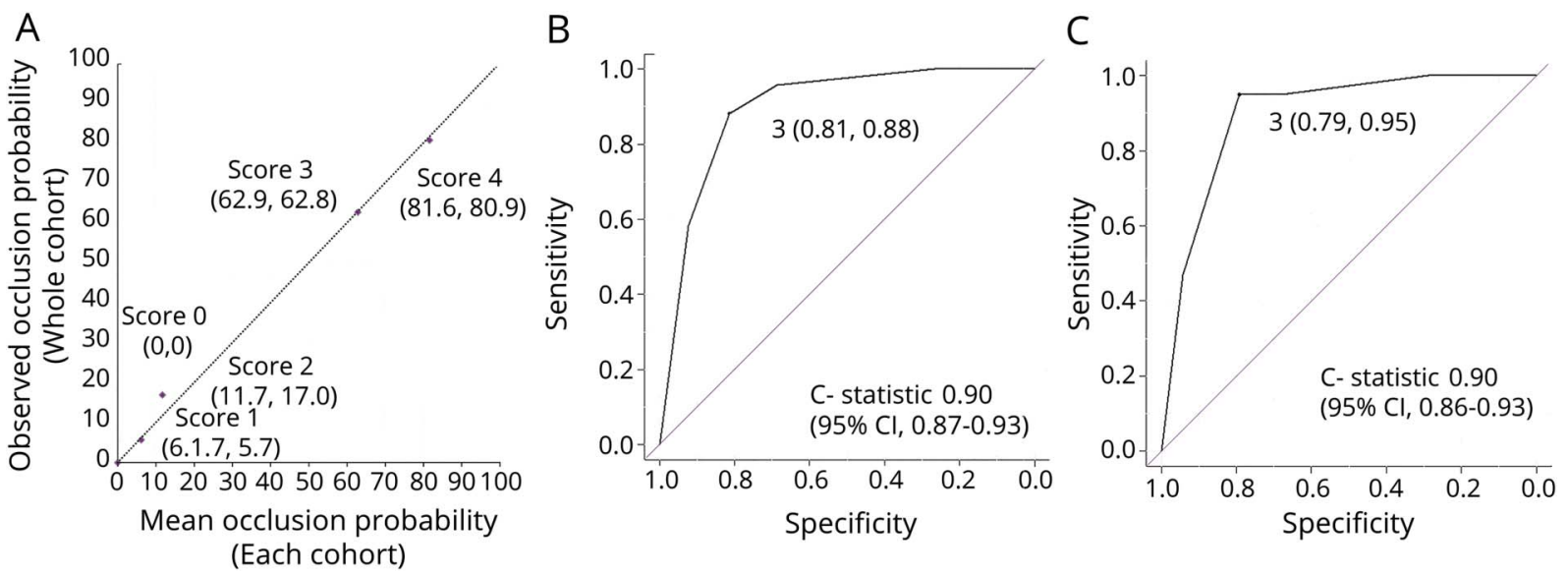

(A) Estimated (x-axis) vs observed (y-axis) values of the probability of an occlusion associated with each score with a reference to the diagonal dotted line, which represents perfect calibration. The receiver operating characteristic curve analysis of the (B) retrospective and (C) prospective cohort showing the sensitivity and specificity of a score of 3 and the $\mathrm{C}$ statistics. $\mathrm{Cl}=$ confidence interval.

of the results of our analysis of a retrospective cohort. Consolidation of 3 hemispheric symptoms is a distinct feature of the $\mathrm{GAI}_{2} \mathrm{AA}$ scale. Acute lesions of the frontal eye fields impair eye movement and cause gaze palsy. ${ }^{42}$ Aphasia is a defect in language processing caused by dysfunction of the dominant cerebral hemisphere. ${ }^{43}$ Contralateral hemineglect often occurs with acute lesions of the nondominant parietal lobes. ${ }^{44}$ These 3 symptoms reflect hemispheric dysfunctions and often coexist and thus may be considered together. Another novel feature of this scale is the double weighting of the presence of GAI. Scores $\geq 3$ always include the GAI symptom.

Scoring, accomplished with a simple model incorporating 4 elements of neurologic deficits, does not grade the clinical elements and is operational in prehospital setting with the information conveyed over the phone. ${ }^{10}$ The scale yielded the same results when applied to retrospective and prospective cohorts. The inclusion of AF prevalence in addition to neurologic deficits is specific to the $\mathrm{GAI}_{2} \mathrm{AA}$ scale. The prevalence of $\mathrm{AF}$ in the general population is $0.95 \%{ }^{45}$; however, it increases to $27 \%$ in patients with acute ischemic stroke with a proximal large anterior circulation occlusion. ${ }^{46}$ Compared with available scales, the $\mathrm{GAI}_{2} \mathrm{AA}$ scale comprises a smaller range of scores with the same efficacy and an apparent cutoff value with high sensitivity (95\%) and sufficient specificity (79\%). The cutoff values of the $\mathrm{GAI}_{2} \mathrm{AA}$ scale $\geq 3$ were associated with false-negative and false-positive rates of $5 \%$ and $21 \%$, respectively, satisfying the required clinical relevance of false-negative and false-positive rates of $\leq 10 \%$ and $\leq 30 \%$, respectively. ${ }^{13}$ A score of 4 always includes $\mathrm{AF}$ and represents a higher probability of an occlusion than does a cutoff score of 3 , which does not necessarily include AF. This suggests that $\mathrm{AF}$ has an additive predictive value by indicating association with cardioembolism. Thus, we believe that the factor AF is clinically relevant and specific to $\mathrm{GAI}_{2} \mathrm{AA}$ scale.
The $\mathrm{GAI}_{2} \mathrm{AA}$ scale is simple and quick to score, so it is useful in time-limited stroke emergencies.

\section{Study limitations}

To minimize lengthy exclusion steps, the study included elderly patients and functionally dependent patients who might not benefit from mechanical thrombectomy. ${ }^{2-6}$ The frequencies of AF vary among different populations. Advancing age, female sex, white race, high income, and large hospital size are associated with increased odds of AF in patients with acute ischemic stroke. ${ }^{47}$ Spontaneous or postalteplase recanalization after scoring may increase the selection of false positives. However, only $21 \%$ of patients had such recanalization after IV alteplase, and as few as $4.4 \%$ patients have ICA occlusion. ${ }^{48}$ To assess the accuracy of a scale for prehospital patient selection, the analysis of all patients suspected to have ischemic stroke, including stroke mimics or hemorrhagic stroke, who were examined in the field might be important. However, reducing the delay in administering mechanical thrombectomy is mandatory, and overestimation of occlusions may be acceptable in a prehospital setting. We included only acute ischemic stroke within 6 hours from onset; however, mechanical thrombectomy is recommended for selected patients within 6 to 16 hours of the last known normal with a proximal large anterior circulation occlusion and meet other DWI or CTP Assessment With Clinical Mismatch in the Triage of Wake-Up and Late Presenting Strokes Undergoing Neurointervention With Trevo $(\mathrm{DAWN})^{49}$ or Endovascular Therapy Following Imaging Evaluation for Ischemic Stroke (DEFUSE 3$)^{50}$ eligibility criteria. ${ }^{7}$ Expanded application of the $\mathrm{GAI}_{2} \mathrm{AA}$ scale requires further verification.

The other simple scales applied to our cohorts showed higher sensitivity than those previously published. ${ }^{10-12,27,28}$ The high 
Table 4 Comparison of the $\mathrm{GAl}_{2} \mathrm{AA}$ scale applied to the retrospective and prospective cohorts with published scales

\begin{tabular}{|c|c|c|c|c|c|c|}
\hline Scores & $\begin{array}{l}\text { Range of } \\
\text { scores }\end{array}$ & $\begin{array}{l}\text { C statistic } \\
(95 \% \mathrm{Cl})\end{array}$ & $\begin{array}{l}p \\
\text { Value }\end{array}$ & $\begin{array}{l}\text { Proposed cutoff } \\
\text { value }\end{array}$ & $\begin{array}{l}\text { Sensitivity, } \\
\%\end{array}$ & $\begin{array}{l}\text { Specificity, } \\
\%\end{array}$ \\
\hline $\mathrm{GAI}_{2} \mathrm{AA}$ scale & $0-4$ & $0.90(0.88-0.92)$ & NA & 3 & 91 & 81 \\
\hline Prehospital Acute Stroke Severity Scale & $0-3$ & $0.87(0.85-0.90)$ & 0.015 & 2 & 90 & 78 \\
\hline Cincinnati Prehospital Stroke Severity Scale & $0-4$ & $0.88(0.85-0.90)$ & 0.075 & 2 & 83 & 86 \\
\hline 3-Item Stroke Scale & $0-6$ & $0.86(0.83-0.89)$ & 0.012 & 4 & 52 & 93 \\
\hline $\begin{array}{l}\text { Field Assessment Stroke Triage for Emergency } \\
\text { Destination }\end{array}$ & $0-9$ & $0.89(0.87-0.92)$ & 0.69 & 4 & 80 & 89 \\
\hline Rapid Arterial Occlusion Evaluation scale & $0-9$ & $0.87(0.84-0.90)$ & 0.052 & 5 & 72 & 89 \\
\hline
\end{tabular}

Abbreviations: $\mathrm{Cl}=$ confidence interval; $\mathrm{NA}=$ not available.

detection rate of neurologic deficits in the present study may reflect the expertise of the attending physicians. This scale may apply only to those tested centers in Japan; further replication in other centers and countries is needed to generalize our study results. To obtain similar results in a prehospital setting, active inquiry of the symptom details from the emergency staff by a stroke-trained physician will likely be useful for accurate detection of the factors of the $\mathrm{GAI}_{2} \mathrm{AA}$ scale, particularly the hemispheric symptoms.

Because of the relatively low specificity, unnecessary use of the angiographic suite and resulting exhaustion of neurointerventionalists might occur. Stroke-trained physicians should check other factors and ensure that the occlusion is reasonable to exclude the unnecessary direct transfer.

\section{Utility of the $\mathrm{GAl}_{2} \mathrm{AA}$ scale}

The $\mathrm{GAI}_{2} \mathrm{AA}$ scale can be a potential beneficial scoring system to help improve outcomes of patients with ischemic stroke due to a proximal large anterior circulation occlusion. Because the scoring performed by a stroke-trained hospital physician was largely dependent on the information provided by the emergency department staff, the simple scoring system of the $\mathrm{GAI}_{2} \mathrm{AA}$ scale can be used by ambulance staff without special training in a prehospital setting. We hope that the score obtained by them alone could be used as screening of the candidates for mechanical thrombectomy. The high sensitivity and good specificity of the $\mathrm{GAI}_{2} \mathrm{AA}$ may justify the omission of cerebral vascular imaging and direct transfer of the patient to an angiographic suite after the exclusion of hemorrhagic strokes if the $\mathrm{GAI}_{2} \mathrm{AA}$ score is $\geq 3$. At least the $\mathrm{GAI}_{2} \mathrm{AA}$ scale can be used as an alert system for mechanical thrombectomy. When multiple, simultaneous admissions of stroke victims occur, adequate patient triage can be achieved with the $\mathrm{GAI}_{2} \mathrm{AA}$ scale scores. Although not perfect, the $\mathrm{GAI}_{2} \mathrm{AA}$ scale is practical in stroke emergencies.

We developed a novel, simple scale to predict a proximal large anterior circulation occlusion based on an analysis within 4.5 hours from onset in a retrospective cohort of patients with

Figure 3 Boxplots of temporal factors associated with mechanical thrombectomy
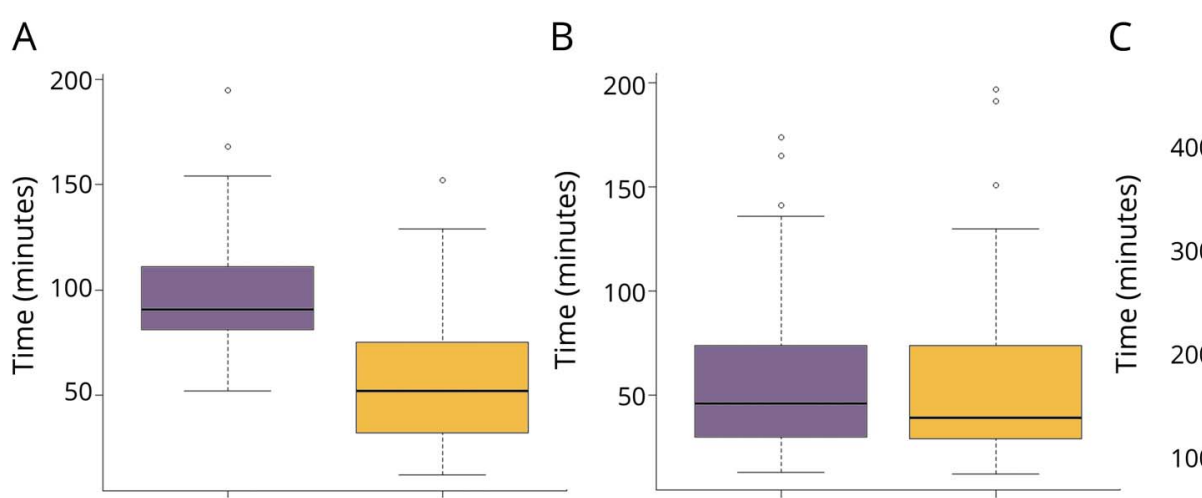

Pre GAI ${ }_{2} A A$ scale

Post GAI ${ }_{2}$ AA scale

Dark line represents median value. Box encloses interquartile range from the first to third quartile. Short horizontal lines represent the minimum and maximum values with the exception of outliers designated with a circle. (A) Door-to-puncture time, (B) puncture-to-recanalization time, and (C) onset-torecanalization time. 
acute ischemic stroke. The $\mathrm{GAI}_{2} \mathrm{AA}$ scale showed high sensitivity and specificity with adequate cutoff scores in the prospective cohort, including patients from 3 stroke centers. Using the $\mathrm{GAI}_{2} \mathrm{AA}$ scale as an in-hospital triage significantly reduced the door-to-puncture time by 40 minutes. The $\mathrm{GAI}_{2} \mathrm{AA}$ scale will likely provide a valuable and highly informative screening tool.

\section{Acknowledgment}

The authors thank MARUZEN-YUSHODO Co, Ltd (kw. maruzen.co.jp/kousei-honyaku/) for the English language editing.

\section{Study funding}

No targeted funding reported.

\section{Disclosure}

T. Ohta reports receiving honoraria for speaking engagements from Stryker and Medicos Hirata and royalties from publishing from Stryker. I. Nakahara reports receiving honoraria for speaking engagements from Cerenovus and Medtronic and research support from Medicos Hirata. S. Matsumoto, D. Kondo, S. Watanabe, and K. Okada report no disclosures relevant to the manuscript. M. Fukuda reports receiving honoraria for speaking engagements from Medicos Hirata and royalties from publishing from Stryker. N. Masahira, T. Tsuno, T. Matsuoka, and M. Takemura report no disclosures relevant to the manuscript. H. Fukuda reports receiving lecture fees from The Supporting Organization for Medical Research and Education in Kochi. N. Fukui reports no disclosures relevant to the manuscript. T. Ueba reports receiving honoraria for a lecture from Daiichi-Sankyo and a grant from The Supporting Organization for Medical Research and Education in Kochi. Go to Neurology.org/ $\mathrm{N}$ for full disclosures.

\section{Publication history}

Received by Neurology February 25, 2019. Accepted in final form July 15, 2019.

Appendix Authors

\begin{tabular}{|c|c|c|c|}
\hline Name & Location & Role & Contribution \\
\hline $\begin{array}{l}\text { Tsuyoshi } \\
\text { Ohta, MD, } \\
\text { PhD }\end{array}$ & $\begin{array}{l}\text { Kochi Health } \\
\text { Sciences } \\
\text { Center, } \\
\text { Japan }\end{array}$ & $\begin{array}{l}\text { Principal } \\
\text { investigator } \\
\text { and } \\
\text { corresponding } \\
\text { author }\end{array}$ & $\begin{array}{l}\text { Design and } \\
\text { conceptualized the } \\
\text { study; analyzed the } \\
\text { data; performed the } \\
\text { statistical analysis; } \\
\text { drafted the } \\
\text { manuscript for } \\
\text { intellectual content }\end{array}$ \\
\hline $\begin{array}{l}\text { Ichiro } \\
\text { Nakahara, } \\
\text { MD, PhD }\end{array}$ & $\begin{array}{l}\text { Fujita Health } \\
\text { University, } \\
\text { Aichi, Japan }\end{array}$ & Author & $\begin{array}{l}\text { Design and } \\
\text { conceptualized the } \\
\text { study; revised the } \\
\text { manuscript for } \\
\text { intellectual content }\end{array}$ \\
\hline $\begin{array}{l}\text { Shoji } \\
\text { Matsumoto, } \\
\text { MD, PhD }\end{array}$ & $\begin{array}{l}\text { Fujita Health } \\
\text { University, } \\
\text { Aichi, Japan }\end{array}$ & Author & $\begin{array}{l}\text { Revised the } \\
\text { manuscript for } \\
\text { intellectual content }\end{array}$ \\
\hline
\end{tabular}

Appendix (continued)

\begin{tabular}{|c|c|c|c|}
\hline Name & Location & Role & Contribution \\
\hline $\begin{array}{l}\text { Daisuke } \\
\text { Kondo, MD }\end{array}$ & $\begin{array}{l}\text { Kokura } \\
\text { Memorial } \\
\text { Hospital, } \\
\text { Fukuoka, } \\
\text { Japan }\end{array}$ & Author & $\begin{array}{l}\text { Major role in the } \\
\text { acquisition of data; } \\
\text { analyzed the data }\end{array}$ \\
\hline $\begin{array}{l}\text { Sadayoshi } \\
\text { Watanabe, } \\
\text { MD }\end{array}$ & $\begin{array}{l}\text { Fujita Health } \\
\text { University, } \\
\text { Aichi, Japan }\end{array}$ & Author & $\begin{array}{l}\text { Major role in the } \\
\text { acquisition of data; } \\
\text { analyzed the data }\end{array}$ \\
\hline $\begin{array}{l}\text { Kenji Okada, } \\
\text { MD }\end{array}$ & $\begin{array}{l}\text { Kochi Health } \\
\text { Sciences } \\
\text { Center, } \\
\text { Japan }\end{array}$ & Author & $\begin{array}{l}\text { Major role in the } \\
\text { acquisition of data; } \\
\text { analyzed the data }\end{array}$ \\
\hline $\begin{array}{l}\text { Maki } \\
\text { Fukuda, MD }\end{array}$ & $\begin{array}{l}\text { Kochi Health } \\
\text { Sciences } \\
\text { Center, } \\
\text { Japan }\end{array}$ & Author & $\begin{array}{l}\text { Interpreted the data; } \\
\text { revised the } \\
\text { manuscript for } \\
\text { intellectual content }\end{array}$ \\
\hline $\begin{array}{l}\text { Noritaka } \\
\text { Masahira, } \\
\text { MD, PhD }\end{array}$ & $\begin{array}{l}\text { Kochi Health } \\
\text { Sciences } \\
\text { Center, } \\
\text { Japan }\end{array}$ & Author & $\begin{array}{l}\text { Interpreted the data; } \\
\text { revised the } \\
\text { manuscript for } \\
\text { intellectual content }\end{array}$ \\
\hline $\begin{array}{l}\text { Takaya } \\
\text { Tsuno, MD, } \\
\text { PhD }\end{array}$ & $\begin{array}{l}\text { Kochi Health } \\
\text { Sciences } \\
\text { Center, } \\
\text { Japan }\end{array}$ & Author & $\begin{array}{l}\text { Interpreted the data; } \\
\text { revised the } \\
\text { manuscript for } \\
\text { intellectual content }\end{array}$ \\
\hline $\begin{array}{l}\text { Toshiki } \\
\text { Matsuoka, } \\
\text { MD }\end{array}$ & $\begin{array}{l}\text { Kochi Health } \\
\text { Sciences } \\
\text { Center, } \\
\text { Japan }\end{array}$ & Author & $\begin{array}{l}\text { Interpreted the data; } \\
\text { revised the } \\
\text { manuscript for } \\
\text { intellectual content }\end{array}$ \\
\hline $\begin{array}{l}\text { Mitsuhiro } \\
\text { Takemura, } \\
\text { MD }\end{array}$ & $\begin{array}{l}\text { Kochi Health } \\
\text { Sciences } \\
\text { Center, } \\
\text { Japan }\end{array}$ & Author & $\begin{array}{l}\text { Interpreted the data; } \\
\text { revised the } \\
\text { manuscript for } \\
\text { intellectual content }\end{array}$ \\
\hline $\begin{array}{l}\text { Hitoshi } \\
\text { Fukuda, MD, } \\
\text { PhD }\end{array}$ & $\begin{array}{l}\text { Kochi } \\
\text { Medical } \\
\text { University, } \\
\text { Japan }\end{array}$ & Author & $\begin{array}{l}\text { Drafting or revising } \\
\text { the manuscript for } \\
\text { intellectual content }\end{array}$ \\
\hline $\begin{array}{l}\text { Naoki Fukui, } \\
\text { MD }\end{array}$ & $\begin{array}{l}\text { Kochi } \\
\text { Medical } \\
\text { University, } \\
\text { Japan }\end{array}$ & Author & $\begin{array}{l}\text { Drafting or revising } \\
\text { the manuscript for } \\
\text { intellectual content }\end{array}$ \\
\hline $\begin{array}{l}\text { Tetsuya } \\
\text { Ueba, MD, } \\
\text { PhD }\end{array}$ & $\begin{array}{l}\text { Kochi } \\
\text { Medical } \\
\text { University, } \\
\text { Japan }\end{array}$ & Author & $\begin{array}{l}\text { Drafting or revising } \\
\text { the manuscript for } \\
\text { intellectual content }\end{array}$ \\
\hline
\end{tabular}

\section{References}

1. Mukherjee D, Patil CG. Epidemiology and the global burden of stroke. World Neurosurg 2011;76:S85-S90.

2. Berkhemer OA, Fransen PS, Beumer D, et al. A randomized trial of intraarterial treatment for acute ischemic stroke. N Engl J Med 2015;372:11-20.

3. Campbell BC, Mitchell PJ, Kleinig TJ, et al. Endovascular therapy for ischemic stroke with perfusion-imaging selection. N Engl J Med 2015;372:1009-1018.

4. Saver JL, Goyal M, Bonafe A, et al. Solitaire with the Intention for Thrombectomy as Primary Endovascular Treatment for Acute Ischemic Stroke (SWIFT PRIME) trial: protocol for a randomized, controlled, multicenter study comparing the Solitaire revascularization device with IV tPA with IV tPA alone in acute ischemic stroke. Int J Stroke 2015;10:439-448.

5. Jovin TG, Chamorro A, Cobo E, et al. Thrombectomy within 8 hours after symptom onset in ischemic stroke. N Engl J Med 2015;372:2296-2306.

6. Saver JL, Goyal M, Bonafe A, et al. Stent-retriever thrombectomy after intravenous t-PA vs. t-PA alone in stroke. N Engl J Med 2015;372:2285-2295.

7. Powers WJ, Rabinstein AA, Ackerson T, et al. 2018 Guidelines for the early management of patients with acute ischemic stroke: a guideline for healthcare professionals from the American Heart Association/American Stroke Association. Stroke 2018;49:e46-e110. 
8. Meretoja A, Keshtkaran M, Tatlisumak T, Donnan GA, Churilov L. Endovascular therapy for ischemic stroke: save a minute-save a week. Neurology 2017;88: 2123-2127.

9. Heldner MR, Hsieh K, Broeg-Morvay A, et al. Clinical prediction of large vessel occlusion in anterior circulation stroke: mission impossible? J Neurol 2016;263: 1633-1640.

10. Hastrup S, Damgaard D, Johnsen SP, Andersen G. Prehospital acute stroke severity scale to predict large artery occlusion: design and comparison with other scales. Stroke 2016;47:1772-1776.

11. Lima FO, Silva GS, Furie KL, et al. Field assessment stroke triage for emergency destination: a simple and accurate prehospital scale to detect large vessel occlusion strokes. Stroke 2016;47:1997-2002.

12. Katz BS, McMullan JT, Sucharew H, Adeoye O, Broderick JP. Design and validation of a prehospital scale to predict stroke severity: Cincinnati Prehospital Stroke Severity Scale. Stroke 2015;46:1508-1512.

13. Turc G, Maier B, Naggara O, et al. Clinical scales do not reliably identify acute ischemic stroke patients with large-artery occlusion. Stroke 2016;47:1466-1472.

14. Collins GS, Reitsma JB, Altman DG, Moons KG. Transparent Reporting of a Multivariable Prediction Model for Individual Prognosis or Diagnosis (TRIPOD): the TRIPOD statement. Ann Intern Med 2015;162:55-63.

15. Nor AM, Davis J, Sen B, et al. The Recognition of Stroke in the Emergency Room (ROSIER) Scale: development and validation of a stroke recognition instrument. Lancet Neurol 2005;4:727-734.

16. Rayburn WF. Diagnosis and classification of diabetes mellitus: highlights from the American Diabetes Association. J Reprod Med 1997;42:585-586.

17. National Cholesterol Education Program Expert Panel on Detection, Evaluation, and Treatment of High Blood Cholesterol in Adults. Third report of the National Cholesterol Education Program (NCEP) Expert Panel on Detection, Evaluation, and Treatment of High Blood Cholesterol in Adults (Adult Treatment Panel III) final report. Circulation 2002;106:3143-3421.

18. O’Donnell MJ, Xavier D, Liu L, et al. Risk factors for ischaemic and intracerebral haemorrhagic stroke in 22 countries (the INTERSTROKE study): a case-control study. Lancet 2010;376:112-123.

19. January CT, Wann LS, Alpert JS, et al. 2014 AHA/ACC/HRS guideline for the management of patients with atrial fibrillation: a report of the American College of Cardiology/American Heart Association Task Force on Practice Guidelines and the Heart Rhythm Society. Circulation 2014;130:e199-e267.

20. Willenbring ML, Massey SH, Gardner MB. Helping patients who drink too much: an evidence-based guide for primary care clinicians. Am Fam Physician 2009;80:44-50.

21. Weng WC, Huang WY, Chien YY, et al. The impact of smoking on the severity of acute ischemic stroke. J Neurol Sci 2011;308:94-97.

22. Puetz V, Dzialowski I, Coutts SB, et al. Frequency and clinical course of stroke and transient ischemic attack patients with intracranial nonocclusive thrombus on computed tomographic angiography. Stroke 2009;40:193-199.

23. Smith WS, Lev MH, English JD, et al. Significance of large vessel intracranial occlusion causing acute ischemic stroke and TIA. Stroke 2009;40:3834-3840.

24. Boslaugh S. Statistics in a Nutshell, 2nd ed. Newton, MA: O’Reilly; 2013.

25. Ely EW, Shintani A, Truman B, et al. Delirium as a predictor of mortality in mechanically ventilated patients in the intensive care unit. JAMA 2004;291: 1753-1762.

26. Collins GS, Ogundimu EO, Altman DG. Sample size considerations for the external validation of a multivariable prognostic model: a resampling study. Stat Med 2016;35: 214-226.

27. Singer OC, Dvorak F, du Mesnil de Rochemont R, Lanfermann H, Sitzer M, Neumann-Haefelin T. A simple 3-Item Stroke Scale: comparison with the National Institutes of Health Stroke Scale and prediction of middle cerebral artery occlusion. Stroke 2005;36:773-776.

28. Perez de la Ossa N, Carrera D, Gorchs M, et al. Design and validation of a prehospital stroke scale to predict large arterial occlusion: the Rapid Arterial Occlusion Evaluation Scale. Stroke 2014;45:87-91.
29. Zhao H, Pesavento L, Coote S, et al. Ambulance clinical triage for acute stroke treatment: paramedic triage algorithm for large vessel occlusion. Stroke 2018;49: 945-951.

30. Nazliel B, Starkman S, Liebeskind DS, et al. A brief prehospital stroke severity scale identifies ischemic stroke patients harboring persisting large arterial occlusions. Stroke 2008;39:2264-2267.

31. McTaggart RA, Ansari SA, Goyal M, et al. Initial hospital management of patients with emergent large vessel occlusion (ELVO): report of the Standards and Guidelines Committee of the Society of NeuroInterventional Surgery. J Neurointerv Surg 2017; 9:316-323.

32. Peduzzi P, Concato J, Kemper E, Holford TR, Feinstein AR. A simulation study of the number of events per variable in logistic regression analysis. J Clin Epidemiol 1996;49: 1373-1379.

33. DeLong ER, DeLong DM, Clarke-Pearson DL. Comparing the areas under two or more correlated receiver operating characteristic curves: a nonparametric approach. Biometrics 1988;44:837-845.

34. Kanda Y. Investigation of the freely available easy-to-use software "EZR" for medical statistics. Bone Marrow Transpl 2013;48:452-458.

35. Fischer U, Arnold M, Nedeltchev K, et al. NIHSS score and arteriographic findings in acute ischemic stroke. Stroke 2005;36:2121-2125.

36. Meyer BC, Hemmen TM, Jackson CM, Lyden PD. Modified National Institutes of Health Stroke Scale for use in stroke clinical trials: prospective reliability and validity. Stroke 2002;33:1261-1266.

37. Meyer BC, Lyden PD. The modified National Institutes of Health Stroke Scale: its time has come. Int J Stroke 2009;4:267-273.

38. Abdul-Rahim AH, Fulton RL, Sucharew H, et al. National Institutes of Health Stroke Scale item profiles as predictor of patient outcome: external validation on independent trial data. Stroke 2015;46:395-400.

39. Kesinger MR, Sequeira DJ, Buffalini S, Guyette FX. Comparing National Institutes of Health Stroke Scale among a stroke team and helicopter emergency medical service providers. Stroke 2015;46:575-578.

40. Tirschwell DL, Longstreth WT Jr, Becker KJ, et al. Shortening the NIH Stroke Scale for use in the prehospital setting. Stroke 2002;33:2801-2806.

41. Kothari R, Hall K, Brott T, Broderick J. Early stroke recognition: developing an out-ofhospital NIH Stroke Scale. Acad Emerg Med 1997;4:986-990.

42. Tijssen CC. Contralateral conjugate eye deviation in acute supratentorial lesions. Stroke 1994;25:1516-1519.

43. Mesulam MM. Large-scale neurocognitive networks and distributed processing for attention, language, and memory. Ann Neurol 1990;28:597-613.

44. Hier DB, Mondlock J, Caplan LR. Behavioral abnormalities after right hemisphere stroke. Neurology 1983;33:337-344.

45. Go AS, Hylek EM, Phillips KA, et al. Prevalence of diagnosed atrial fibrillation in adults: national implications for rhythm management and stroke prevention: the AnTicoagulation and Risk Factors in Atrial Fibrillation (ATRIA) Study. JAMA 2001; 285:2370-2375

46. Heshmatollah A, Fransen PSS, Berkhemer OA, et al. Endovascular thrombectomy in patients with acute ischaemic stroke and atrial fibrillation: a MR CLEAN subgroup analysis. EuroIntervention 2017;13:996-1002.

47. Otite FO, Khandelwal P, Chaturvedi S, Romano JG, Sacco RL, Malik AM. Increasing atrial fibrillation prevalence in acute ischemic stroke and TIA. Neurology 2016;87: 2034-2042.

48. Bhatia $\mathrm{R}$, Hill MD, Shobha $\mathrm{N}$, et al. Low rates of acute recanalization with intravenous recombinant tissue plasminogen activator in ischemic stroke: real-world experience and a call for action. Stroke 2010;41:2254-2258.

49. Nogueira RG, Jadhav AP, Haussen DC, et al. Thrombectomy 6 to 24 hours after stroke with a mismatch between deficit and infarct. N Engl J Med 2018;378:11-21.

50. Albers GW, Marks MP, Kemp S, et al. Thrombectomy for stroke at 6 to 16 hours with selection by perfusion imaging. N Engl J Med 2018;378:708-718. 


\section{Neurology}

Optimizing in-hospital triage for large vessel occlusion using a novel clinical scale (GAI 2AA)

Tsuyoshi Ohta, Ichiro Nakahara, Shoji Matsumoto, et al.

Neurology 2019;93;e1997-e2006 Published Online before print October 24, 2019

DOI 10.1212/WNL.0000000000008550

This information is current as of October 24, 2019

\section{Updated Information \&} Services

References

Citations

Subspecialty Collections

Permissions \& Licensing

Reprints including high resolution figures, can be found at: http://n.neurology.org/content/93/22/e1997.full

This article cites 49 articles, 24 of which you can access for free at: http://n.neurology.org/content/93/22/e1997.full\#ref-list-1

This article has been cited by 5 HighWire-hosted articles: http://n.neurology.org/content/93/22/e1997.full\#\#otherarticles

This article, along with others on similar topics, appears in the following collection(s):

Clinical trials Observational study (Cohort, Case control)

http://n.neurology.org/cgi/collection/clinical_trials_observational_stud y_cohort_case_control

Critical care

http://n.neurology.org/cgi/collection/critical_care

\section{Infarction}

http://n.neurology.org/cgi/collection/infarction

Information about reproducing this article in parts (figures,tables) or in its entirety can be found online at:

http://www.neurology.org/about/about_the_journal\#permissions

Information about ordering reprints can be found online:

http://n.neurology.org/subscribers/advertise

Neurology ${ }^{\circledR}$ is the official journal of the American Academy of Neurology. Published continuously since 1951, it is now a weekly with 48 issues per year. Copyright Copyright (C) 2019 The Author(s). Published by Wolters Kluwer Health, Inc. on behalf of the American Academy of Neurology.. All rights reserved. Print ISSN: 0028-3878. Online ISSN: 1526-632X.

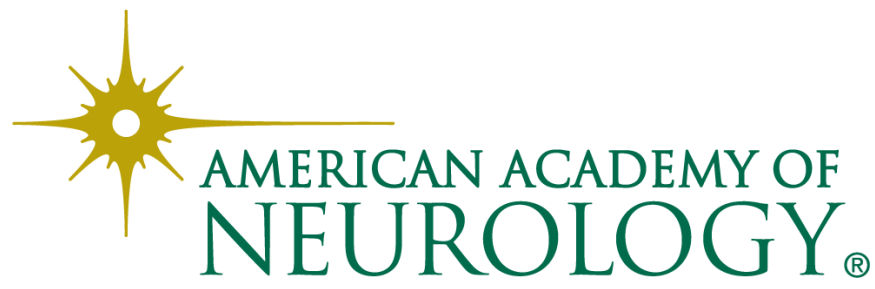

